\title{
Verificação de um modelo computacional baseado no método de elementos finitos aplicado à flambagem biaxial de placas delgadas laminadas
}

Verification of computational model based in finite element method applied to biaxial buckling in thin laminated plates

\author{
T. da Silveira ${ }^{1 *}$ J. P. S. Lima ${ }^{1}$; M. V. Real ${ }^{1,2}$; L. A. O. Rocha ${ }^{3}$ E. D. dos $\operatorname{Santos}^{1,2}$, \\ L. A. Isoldi ${ }^{1,2}$ \\ ${ }^{1}$ Programa de Pós-Graduação em Engenharia Oceânica, Universidade Federal do Rio Grande, 96201-900, Rio \\ Grande-RS, Brasil \\ ${ }^{2}$ Programa de Pós-Graduação em Modelagem Computacional, Universidade Federal do Rio Grande, 96201-900, Rio \\ Grande-RS, Brasil \\ ${ }^{3}$ Programa de Pós-Graduação em Engenharia Mecânica, Universidade Federal do Rio Grande do Sul, 90050-170, \\ Porto Alegre-RS, Brasil
}

*engmects@hotmail.com

(Recebido em 11 de maio de 2017; aceito em 22 de maio de 2017)

\begin{abstract}
Placas finas perfuradas são muito utilizadas nas indústrias naval e aeronáutica. Em se tratando de meios oceânicos, placas laminadas apresentam uma grande vantagem em relação ao aço, a resistência à corrosão marinha. Porém, um fenômeno de instabilidade conhecido como flambagem elástica pode surgir, comprometendo a integridade da estrutura, quando essas placas finas estão submetidas a cargas de compressão. Dois modelos computacionais são avaliados para que se comprove a eficiência do Método de Elementos Finitos, através do software comercial ANSYS®, com a utilização do elemento de casca SHELL281. Duas placas são verificadas, uma primeira retangular sem perfurações e uma segunda placa, retangular, com a aplicação de um furo circular central. Observou-se que o SHELL281 pode ser adequadamente utilizado para a análise da carga crítica de flambagem elástica em placas de material compósito, com ou sem furos. Também, quando se trata de uma placa com furo, percebe-se que a carga crítica de flambagem reduz à medida que a espessura da placa diminui. Para placas perfuradas, quando variando uma razão do comprimento da placa em relação ao eixo $x$ pela espessura $(L / h)$, entre 20 e 100 , chega-se à conclusão que a menor carga crítica de flambagem $(L / h=100)$ representa apenas $0,88 \%$ da melhor carga crítica obtida, quando $L / h=20$.
\end{abstract}

Palavras-chave: Método de Elementos Finitos, Flambagem, Compósitos, Placa delgada

Plates with cutouts are constantly used in naval and aeronautic engineering. When considered oceanic environment, laminated plates present an advantage against steel plates, the corrosion resistance. However, the instability phenomenon named as elastic buckling can affect the structure integrity when these thin plates are under compressive loads. Two computational models are evaluated to verify the efficiency of Finite Element Method applied through the software ANSYS®, using the shell element SHELL281. Two rectangular plates are verified, one without cutouts and other plate with circular cutout applied in the center of plate. It was observed that SHELL281 can be adequately applied to analyze the elastic critical buckling load in laminated plates with or without cutouts. Regarding the plate with cutout, the critical buckling load decreases as long as plate thickness decreases. For plate with cutout, when changing the fraction plate length/plate thickness $(L / h)$, between 20 and 100, is noted that the smaller critical load found $(L / h=100)$ represents only $0,88 \%$ of best critical load found, when $L / h=20$.

Keywords: Finite Element Method, Buckling, Composits, Thin Plates

\section{INTRODUÇÃO}

No Brasil, boa parte da economia ainda se baseia em atividades navais. Embarcações cargueiras atracam diariamente nos portos brasileiros, navios estes que, a cada dia que passa, 
trazem uma quantidade maior de cargas e requerem um calado maior. Em decorrência dos grandes volumes transportados, as estruturas das embarcações devem estar adequadas à capacidade de transporte. Plataformas de perfuração de poços de petróleo, especialmente os navios-sonda de últimas gerações, do inglês Drillships, são embarcações robustas e com grande capacidade para o armazenamento de cargas no deck assim como para as grandes solicitações devido às operações de perfuração. Da mesma forma que nos navios-sonda, as plataformas FPSO, do inglês Floating Production Storage and Offloading, possuem uma grande solicitação estrutural por acomodações de cargas e movimentações relativas ao operacional cotidiano.

Atualmente existem muitas pesquisas em busca de materiais novos, mais leves e resistentes. Exemplo disso são os materiais que utilizam ligas metálicas unidas com tecidos de fibra, apresentando resistência elevada, baixa massa e grande versatilidade na sua utilização. Para as estruturas oceânicas, muito do trabalho é feito de forma conservadora, tendo como principal material de construção o aço. O motivo disto pode ser devido ao fato de que ainda não sejam conhecidos materiais desenvolvidos com as propriedades necessárias ao uso em ambiente oceânico.

O estudo da flambagem de placas finas feitas de material compósito, com e sem perfurações, acrescentará de forma significativa às tecnologias navais, visto que o uso destes componentes pode reduzir consideravelmente o peso de parte das estruturas, inclusive melhorando algumas propriedades da construção final. O material compósito, quando em ambiente marinho, trás uma grande vantagem em relação ao aço no que diz respeito à resistência à corrosão.

Estruturas de placas de material compósito laminado, como a estrutura de uma fuselagem de avião, do casco de navios ou da cápsula de um automóvel, são geralmente expostas a solicitações biaxiais de cargas no seu plano. As formas de flambagem biaxiais geralmente aparecem no plano de placas retangulares, quando estas estruturas estão submetidas a alguma condição de contorno totalmente suportada. Ainda se esta placa for submetida a carregamentos uniaxiais compressivos, a placa pode apresentar estado de tensão biaxial e deve ser revelada uma deflexão biaxial devido às interações dos carregamentos axiais e das forças reativas do contorno [1].

As placas finas ou delgadas são elementos estruturais amplamente utilizados na engenharia naval e oceânica, como por exemplo, em plataformas de extração de petróleo e em embarcações. Sabe-se, porém, que elementos estruturais esbeltos submetidos a cargas de compressão podem falhar de maneira súbita devido a um fenômeno de instabilidade conhecido como flambagem [2].

$\mathrm{Na}$ literatura é possível encontrar estudos sobre a flambagem de placas de material compósito submetidas à flambagem, como em Austin (2003) [3] que aplicou cargas compressivas de flambagem em placas de plástico reforçadas por fibra de vidro (FRP - Fiberglass Reinforced Plastic). Utilizando o MEF através do software ANSYS ${ }^{\circledR}$, foi constatado que dentre os testes realizados, o laminado que apresentou melhor resultado para a carga crítica de flambagem uniaxial foi o com esquema de laminação $(90 /+45 /-45)$, quando se tratando de condições de contorno simplesmente apoiadas nas quatro arestas. No entanto, quando trocadas as condições de contorno para três arestas simplesmente apoiadas e uma livre (simples-simples-simples-livre), ou ainda simples-fixa-simples-livre, os melhores resultados foram obtidos para a laminação sob orientação (90/+15/-15) para razões de aspecto menores do que 2 (dois). Isso também mostra que a presença do acoplamento flexão-torção diminui a carga crítica de flambagem do laminado em até 30\%. Já em [4] foram estudados os efeitos da configuração de laminação assimétrica, de furos e da razão comprimento/espessura, na carga crítica de flambagem uniaxial de placas compósitas de fibra de vidro com epoxi (E/glass-epoxy). As cargas críticas foram apresentadas para placas simetricamente e assimetricamente laminadas sujeitas à carregamento axial compressivo. Foi observado que a presença de perfurações reduz a carga crítica de flambagem para todas as configurações testadas e que, de forma geral, o valor obtido para a carga crítica é o mesmo quando o furo é circular ou semi-circular. Também, quando aumentada a relação $L / t$ (comprimento/espessura), há uma redução considerável da carga crítica de flambagem chegando a $75 \%$ de redução quando a relação $L / t$ é incrementada em $50 \%$. Por fim, foi observado que as cargas críticas de flambagem foram maiores quando testadas as configurações de laminação assimétrica, especialmente quando as condições de contorno contemplavam engaste. Normalmente, as placas simplesmente apoiadas apresentaram valores menores do que quando engastadas. 
Em Barbero (2007) [5] é apresentada a simulação de uma placa sem perfurações, sob compressão biaxial, feita com 12 (doze) camadas de grafite-epóxi com 0,85 mm cada. Com a utilização do software ANSYS®, e a seleção do elemento de casca SHELL93, a carga crítica de flambagem elástica biaxial encontrada é igual a $252,70 \mathrm{~N} / \mathrm{mm}$, para uma orientação de laminação $(0 / 90) 3 \mathrm{~s}$.

Já em Al-Qablan et al. (2010) [6], foi utilizado o MEF para encontrar a melhor carga crítica de flambagem para as placas de material compósito, contendo furos e enrijecedores. Três tipos de carregamentos foram utilizados: uniaxial, biaxial e de cisalhamento. Baseado no modelo de estudo, foi observado que o incremento total da carga crítica de flambagem para as placas de material compósito, com furos e utilizando enrijecedores, pode chegar a cinco vezes no carregamento uniaxial, sete vezes no carregamento biaxial e duas vezes no carregamento de cisalhamento, quando comparados os valores obtidos com os resultados da placa sem uso de enrijecedores. Ainda neste estudo, considerando valores pequenos (entre 0,0 e 0,3 ) para as razões entre o diâmetro do furo e a largura da placa, foi possível desconsiderar os efeitos de furos para os casos de solicitação uniaxial e biaxial em placas com enrijecedores. Assim, a carga crítica ótima encontrada respeita valores da mesma razão entre 0,4 e 0,6 , quando a placa apresentou o maior valor de carga suportada antes de sofrer com o fenômeno, indesejado, de instabilidade.

Por fim, em Joshi et al. (2013) [7] é feita a avaliação da carga crítica de flambagem biaxial para placas laminadas retangulares, simétricas, com a aplicação de perfurações circulares. A utilização do software comercial ANSYS® foi executada com sucesso. Para a avaliação das cargas críticas de flambagem, o autor varia a posição dos furos circulares ao longo da placa. Em uma segunda análise a geometria da placa é alterada com o incremento da sua dimensão longitudinal, incremento este comandado pela variação da razão $a / b$, onde $a$ é a dimensão da altura da placa (longitudinal) e $b$ é a largura da placa, constante para a análise. Uma terceira análise é feita com a variação da relação $b / t$, onde $t$ é a espessura da placa. É constatado pelo autor que a carga crítica de flambagem reduz com o aumento da razão de aspecto da placa. Conforme aumenta a relação $b / t$, reduz-se a carga crítica de flambagem por unidade de comprimento. A placa com o furo na parte superior apresenta maior carga crítica de flambagem do que os furos central e inferior.

Portanto, o presente trabalho, busca a verificação de dois modelos computacionais para aplicação do MEF, utilizando o software ANSYS $®$, com a finalidade de avaliar o comportamento de placas laminadas simétricas quando solicitadas biaxialmente por carregamentos compressivos. Um dos modelos será verificado com base na placa fina retangular sem perfurações apresentada em Barbero (2007) [5]. O segundo modelo verificado foi aplicado às condições apresentadas em Joshi et al. (2013)[7], onde placas finas retangulares simétricas com perfurações elípticas/circulares submetidas à flambagem biaxial foram simuladas numericamente.

\section{METODOLOGIA}

Nesta pesquisa o software ANSYS®, que é baseado no MEF, foi empregado para a modelagem computacional dos problemas propostos. O ANSYS® é um software comercial, que pode ser utilizado nas mais diversas classes de problemas de engenharia. Possui habilidades para resolver diferentes tipos de análises estruturais, como por exemplo análises estáticas, dinâmicas, modais, harmônicas, espectrais e de flambagem. No ANSYS, para uma análise estrutural, os deslocamentos e as rotações (graus de liberdade nodais) são calculados numericamente, e a partir destes valores outras quantidades, como deformações e tensões, são determinadas [8].

Segundo Zienkiewicz e Taylor (1989) [9] e Bathe (1996) [10], com a evolução da ciência, o MEF vem sendo muito utilizado para obtenção de soluções aproximadas para muitos dos problemas encontrados na análise de engenharia, com boa precisão.

No campo da análise estrutural, o MEF é usualmente adotado em sua formulação de deslocamento. Desta forma, a estrutura é dividida num certo número de pequenas regiões - os chamados elementos finitos. Estes elementos são assumidos como interconectados por um número determinado de pontos nodais localizados em seus limites $[9,10]$. 


\subsection{Elemento de casca SHELL281}

Segundo Real e Isoldi (2010) [11], um conjunto de funções de interpolação é utilizado para definir exclusivamente o estado de deslocamento dentro de cada elemento finito, em termos de deslocamentos de seus nós. O estado de deformação dentro do elemento é definido através das relações deformação-deslocamento. O estado de tensão ao longo do elemento é determinado pela lei de tensão-deformação do material.

Através da aplicação do Princípio dos Trabalhos Virtuais (PTV), as forças nodais correspondentes a um campo de deslocamento no elemento são determinadas. Estas forças nodais estão relacionadas com os deslocamentos nos nós através da matriz de rigidez do elemento. Assim, as condições de equilíbrio global já foram satisfeitas dentro do elemento [11]. Então, aplicando-se as equações de equilibro a cada ponto nodal, estabelece-se o sistema de equações de equilíbrio da estrutura, que uma vez resolvido fornece os deslocamentos nodais.

O ANSYS ${ }^{\circledR}$ foi utilizado na sua versão 14, sendo o elemento de casca SHELL281 adotado para a modelagem computacional. O SHELL281 é adequado para a análise de estruturas de casca laminada com espessura fina até moderada. O elemento tem oito nós e seis graus de liberdade para cada nó, sendo eles: translações ao longo dos eixos $x, y$ e $z$, e rotações em torno dos eixos $x$, $y$ e $z$ [13].

Segundo Ansys (2009) [12], o SHELL281 deve ser utilizado para aplicações laminadas, sendo elas cascas compósitas ou construções sanduíche. O elemento trabalha com a precisão de modelagem, para cascas compósitas, governada pela primeira ordem da teoria de deformação de cisalhamento. O elemento SHELL281 é mostrado na Figura 1.

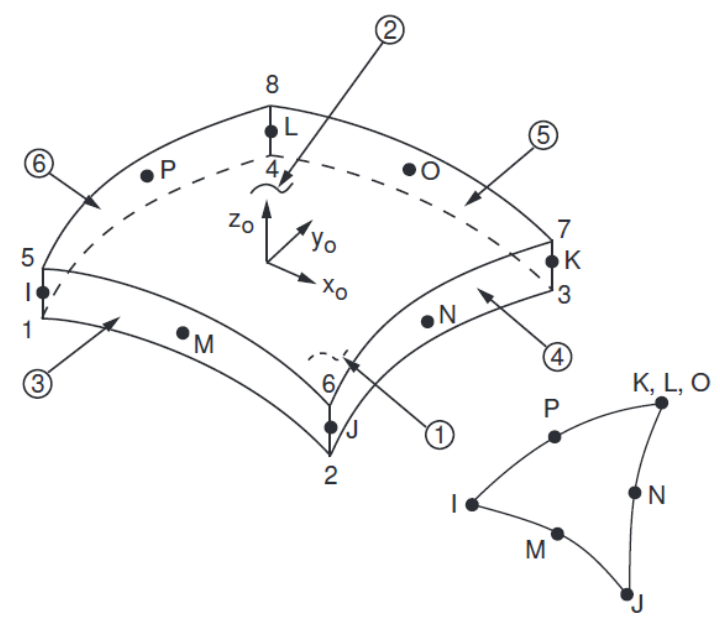

Figura 1 - Geometria do elemento SHELL281 [12].

Para o estudo numérico do fenômeno da flambagem através do programa computacional, é adotada a análise elástica de autovalores. Segundo Madenci e Guven (2006) [13], as equações de equilíbrio por elementos finitos para este tipo de análise envolvem a solução de equações algébricas homogêneas cujo autovalor mais baixo corresponde à carga crítica de flambagem e o autovetor associado representa o modo primário de flambagem. Segundo Przemieniecki (1985) [14], a formulação utilizada para a metodologia de análise inclui tanto os termos lineares como os termos não lineares. Desta forma, a matriz rigidez total $[K]$, é obtida pela soma da matriz de rigidez convencional para pequenas deformações, $\left[K_{E}\right]$, com a matriz de rigidez geométrica $\left[K_{G}\right]$. Esta última, $\left[K_{G}\right]$, não depende apenas da geometria visto que o esforço interno $\left\{P_{0}\right\}$ existente no início do carregamento deve ser considerado. Desta forma, a matriz de rigidez total da placa para um nível de carga $\left\{P_{0}\right\}$ é dada por:

$$
[K]=\left[K_{E}\right]+\left[K_{G}\right]
$$


onde $[K]$ é a matriz de rigidez total, $\left[K_{E}\right]$ é a matriz de rigidez convencional para deformações pequenas e $\left[K_{G}\right]$ é a matriz de rigidez geométrica.

No caso de o carregamento atingir um nível de $\{P\}=\lambda\left\{P_{0}\right\}$, onde $\lambda$ é um escalar, a matriz de rigidez passa a ser escrita como:

$$
[K]=\left[K_{E}\right]+\lambda\left[K_{G}\right]
$$

sendo $\lambda$ um escalar.

As equações, governantes, de equilíbrio para uma placa, podem ser escritas como:

$$
\left[\left[K_{E}\right]+\lambda\left[K_{G}\right]\right]\{U\}=\lambda\left\{P_{0}\right\}
$$

onde $\{U\}$ é o vetor de deslocamento total e $\left\{P_{0}\right\}$ é o esforço interno existente no início do carregamento.

O vetor de deslocamento total pode ser determinado por:

$$
\{U\}=\left[\left[K_{E}\right]+\lambda\left[K_{G}\right]\right]^{-1} \lambda\left\{P_{0}\right\}
$$

Em se tratando de flambagem de placas, o elemento estrutural em análise apresenta um grande crescimento nos deslocamentos sem que haja crescimento da carga. Por definição matemática é possível obter a matriz inversa como a matriz adjunta divida pelo determinante dos coeficientes, então os deslocamentos $\{U\}$ tendem a infinito quando:

$$
\operatorname{det}\left[\left[K_{E}\right]+\lambda\left[K_{G}\right]\right]=0
$$

sendo det o determinante da matriz.

Segundo Ansys (2005) [15], esta equação representa um problema de autovalores que, uma vez resolvido, gera o menor autovalor, $\lambda_{1}$, que corresponde à carga crítica de flambagem dada por $\left\{P_{C r}\right\}=\lambda_{1}\left\{P_{0}\right\}$. Esta é a carga limite onde se inicia o fenômeno de instabilidade da flambagem. Ainda, o vetor de deslocamento associado $\{U\}$ define a forma do modo de flambagem. $\mathrm{O}$ problema de autovalores é resolvido usando o método numérico de Lanczos.

\subsection{Placa laminada sem perfuração}

O presente trabalho contempla placas finas submetidas à solicitação compressiva biaxial, o que resulta em análises de flambagem elástica biaxial. Inicialmente, uma placa sem perfurações, como a apresentada em Ansys (2005) [5], foi considerada para verificar o modelo computacional para a flambagem biaxial de uma placa laminada e delgada, de material compósito. A Figura 2 apresenta a representação esquemática dessa placa. 


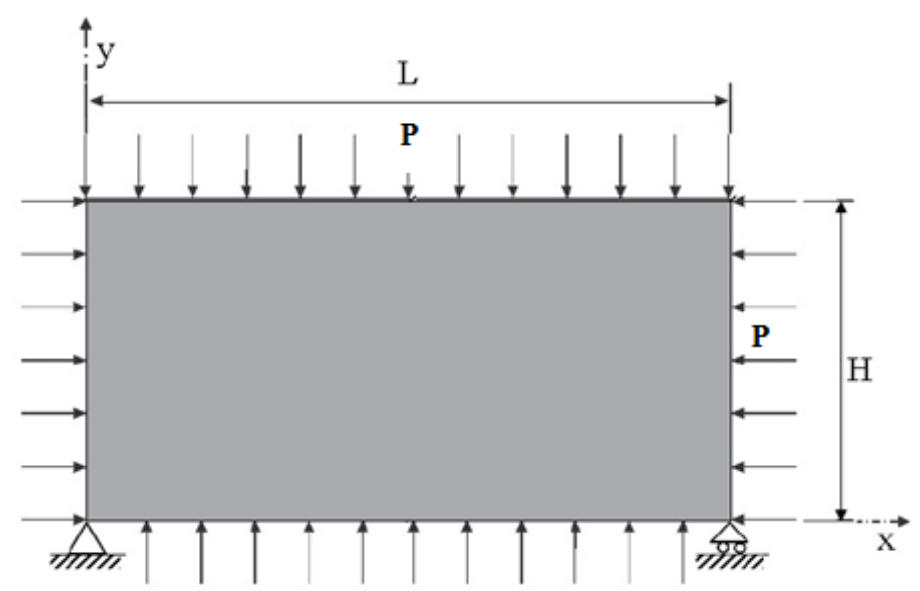

Figura 2 - Placa sem perfurações e simplesmente apoiada nas arestas, submetida à compressão biaxial, sendo $H=500 \mathrm{~mm}$ e $L=1000 \mathrm{~mm}$.

O problema proposto por Barbero (2007) [5] trata de uma placa simplesmente apoiada laminada em AS4/9310 com fração volumétrica de fibras igual a 0,6. O laminado possui dimensões de $500 \mathrm{~mm} \times 1000 \mathrm{~mm} \times 10,2 \mathrm{~mm}$ (divididos em doze camadas de laminação com $0,85 \mathrm{~mm}$ de espessura, cada) com orientação de (0/90)3s.

As propriedades da placa são dadas em função dos eixos 1-2-3, como pode ser visto na Figura 3. Segundo Mendonça (2005) [16], a direção das fibras define as três direções principais de propriedades de uma lâmina, que são as direções tomadas como referência nas definições das propriedades mecânicas, tensões, deformações e demais cálculos básicos.

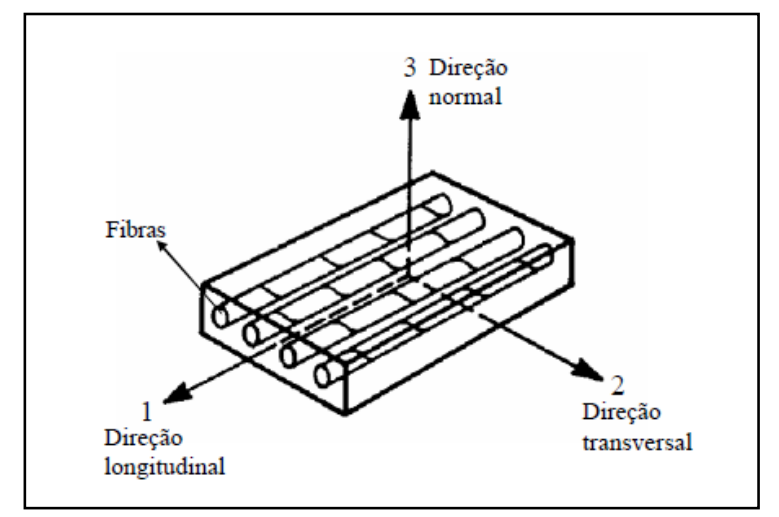

Figura 3 - Direções Principais da propriedade de uma lâmina [17].

A placa usada na verificação apresenta propriedades de engenharia referenciadas aos eixos 12-3 mostrados na Figura 3. $E_{1}, E_{2}$ e $E_{3}$ os módulos de Young nas direções principais 1,2 e $3 ; v_{12}$, $v_{13}$ e $v_{23}$ são os valores de coeficiente de Poisson; $G_{12}, G_{13}$ e $G_{23}$ são os módulos de elasticidade transversal cisalhante, nos planos 1-2, 2-3 e 3-1, respectivamente. Então, as propriedades mecânicas da placa da Figura 2 são, $E_{1}=145880 \mathrm{MPa}, E_{2}=E_{3}=13312 \mathrm{MPa}, G_{12}=G_{13}=4386$ $\mathrm{MPa}, G_{23}=4529 \mathrm{MPa}, v_{12}=v_{13}=0,263$ e $v_{23}=0,470$.

\subsection{Placa laminada com perfuração central}

Outra verificação do modelo computacional desenvolvido com SHELL281 foi feita para uma placa laminada fina retangular, submetida à solicitação compressiva biaxial, possuindo uma perfuração central circular. Para isso, uma placa analisada por Joshi et al. (2013) [7] foi utilizada. A Figura 4 apresenta a placa utilizada nesta verificação. 


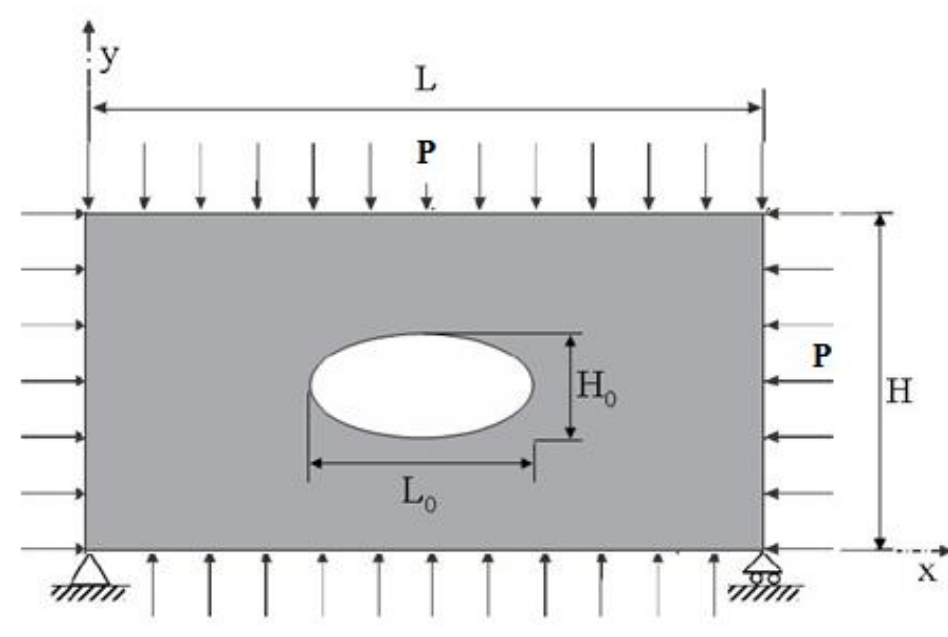

Figura 4 - Placa com furo elíptico centrado.

Em Joshi et al. (2013) [7] foi utilizada uma placa laminada simétrica de fibra epoxy/carbono, de laminação (0/45)2s com altura $H=2000 \mathrm{~mm}$, largura $L=1000 \mathrm{~mm}$ e espessura variando em razões $L / h$, onde $h$ é a espessura. O furo avaliado é circular com diâmetro de $500 \mathrm{~mm}$, ou seja, $H_{0}=L_{0}=500 \mathrm{~mm}$. A Tabela 1 apresenta as propriedades do material utilizado, bem como a configuração da placa.

\begin{tabular}{cc} 
Tabela 1: Propriedades Mecânicas da placa com furo \\
\hline Propriedade & Valor \\
\hline $\mathbf{E}_{\mathbf{1}}$ & $\mathbf{1 3 9 0 0 0} \mathbf{M P a}$ \\
$\mathbf{E}_{2}=\mathbf{E}_{\mathbf{3}}$ & $\mathbf{1 1 0 0 0} \mathbf{M P a}$ \\
$\mathbf{G}_{\mathbf{1 2}}=\mathbf{G}_{\mathbf{1 3}}$ & $\mathbf{4 7 0 0} \mathrm{MPa}$ \\
$\mathbf{G}_{\mathbf{2 3}}$ & $\mathbf{3 7 0 0} \mathrm{MPa}$ \\
$\mathbf{v}_{\mathbf{1 2}}=\mathbf{v}_{\mathbf{1 3}}$ & $\mathbf{0 , 3 2 0}$ \\
$\mathbf{v}_{\mathbf{2 3}}$ & $\mathbf{0 , 4 6 0}$ \\
\hline
\end{tabular}

\section{RESULTADOS E DISCUSSÃO}

Como descrito no item 2 deste estudo, o MEF é o método utilizado para a obtenção dos resultados apresentados a seguir. As duas análises feitas são apresentadas a seguir, sendo o primeiro caso o da placa sem furo como exposto no item 2.2. A seguir, a análise da placa com furo central é feita, respeitando o descrito no item 2.3.

\subsection{Placa sem perfuração}

Barbero (2007) [5] utiliza um modelo computacional desenvolvido no software ANSYS®, versão 12 e elemento de casca SHELL93. Para o modelo computacional desenvolvido no presente estudo, foi utilizada uma versão mais recente do software ANSYS ${ }^{\circledR}$, ANSYS 14, e o elemento de casca utilizado foi o SHELL281.

Com o elemento SHELL93 uma carga crítica de $252,70 \mathrm{~N} / \mathrm{mm}$ foi obtida [5]. E com o modelo utilizando o elemento SHELL281, a carga crítica de flambagem obtida foi de $252,70 \mathrm{~N} / \mathrm{mm}$, o que verifica o modelo computacional, para a flambagem elástica de uma placa sem perfurações, utilizado nessa pesquisa. A configuração flambada da placa pode ser vista na Figura 5, onde 0 
(zero) indica deslocamento nulo e está representado em azul e 1 (um) representa o máximo deslocamento mostrado em vermelho.

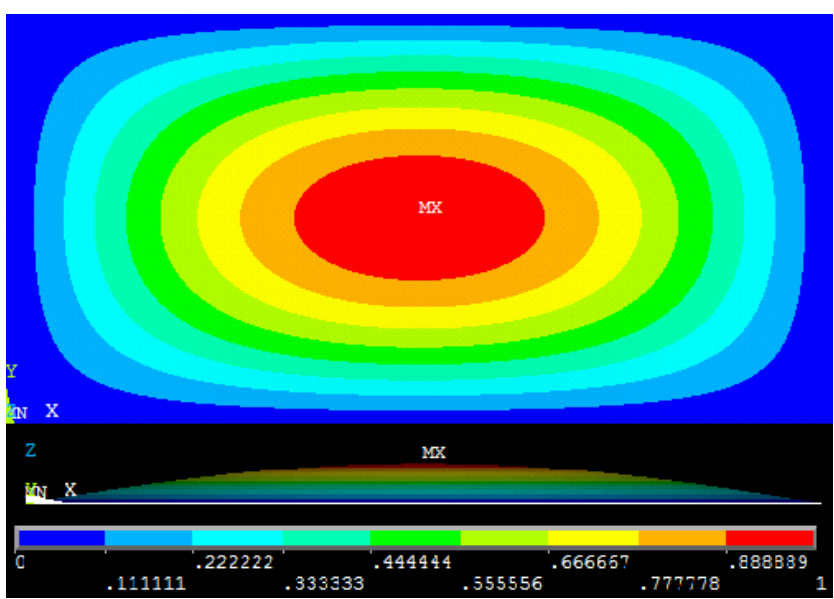

Figura 5 - Placa utilizada para verificação do modelo computacional, em seu primeiro modo de flambagem causado por uma carga crítica de 252,70 N/mm.

\subsection{Placa com perfuração elíptica central}

A Tabela 2 apresenta os resultados obtidos após a simulação da placa perfurada utilizando o elemento de casca SHELL281, considerando diferentes valores para a razão $L / h$. Na referência Joshi et al. (2013) [7] foi empregado o elemento SHELL99 para as suas análises e foram gerados gráficos com as curvas representativas das cargas críticas de flambagem.

\begin{tabular}{|c|c|c|}
\hline$H / L$ & $L / h$ & $\operatorname{PCr}(\mathrm{N} / \mathrm{mm})$ \\
\hline 2 & 20 & 6733,04 \\
\hline 2 & 40 & 896,08 \\
\hline 2 & 60 & 270,89 \\
\hline 2 & 80 & 115,50 \\
\hline 2 & 100 & 59,54 \\
\hline
\end{tabular}

Pode-se perceber que a carga crítica diminui, conforme a relação $L / h$ aumenta. Em outras palavras, o valor da carga crítica de flambagem biaxial em placas laminadas perfuradas diminui à medida que a espessura da placa diminui. Observando os valores obtidos, pode-se notar que a menor carga crítica obtida, para um $L / h=100$, representa apenas $0,88 \%$ do maior valor obtido, quando $L / h=20$, que resulta em um $P C r=6733,04 \mathrm{~N} / \mathrm{mm}$. A mesma conclusão pode ser observada na Figura 6 que apresenta a comparação da curva obtida por Joshi et al. (2013) [7] e a curva obtida no presente estudo. Com a comparação das curvas percebe-se o mesmo comportamento das placas, verificando o modelo computacional deste trabalho. 


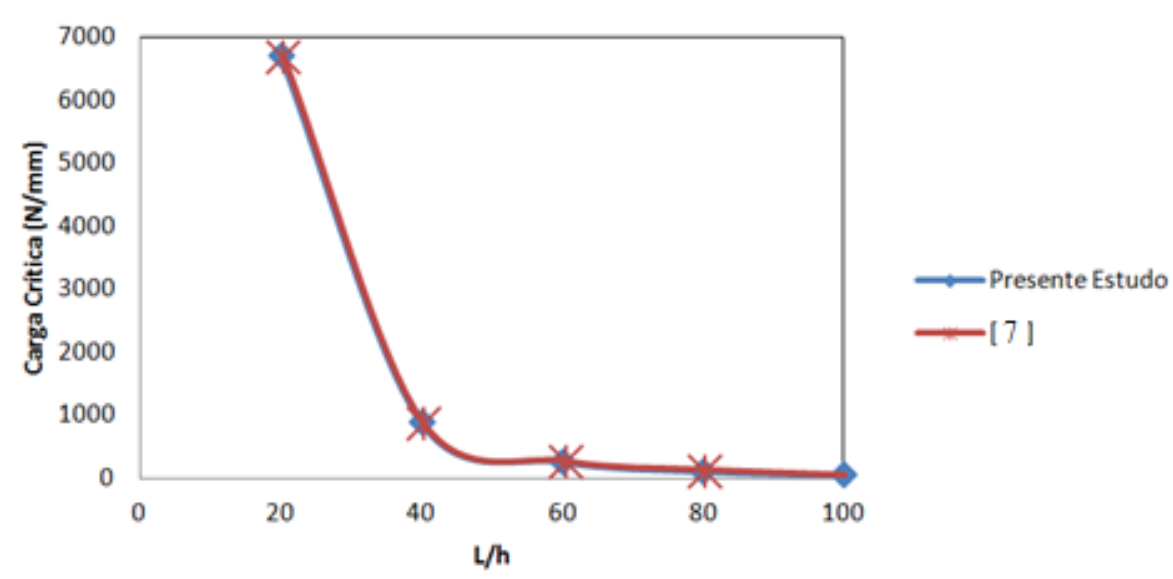

Figura 6 - Comparação das curvas de carga crítica entre [7] e o presente trabalho.

A configuração flambada da placa, com $L / h=20$, no seu primeiro modo de flambagem elástica, obtido numericamente no presente estudo, pode ser vista na Figura 7.

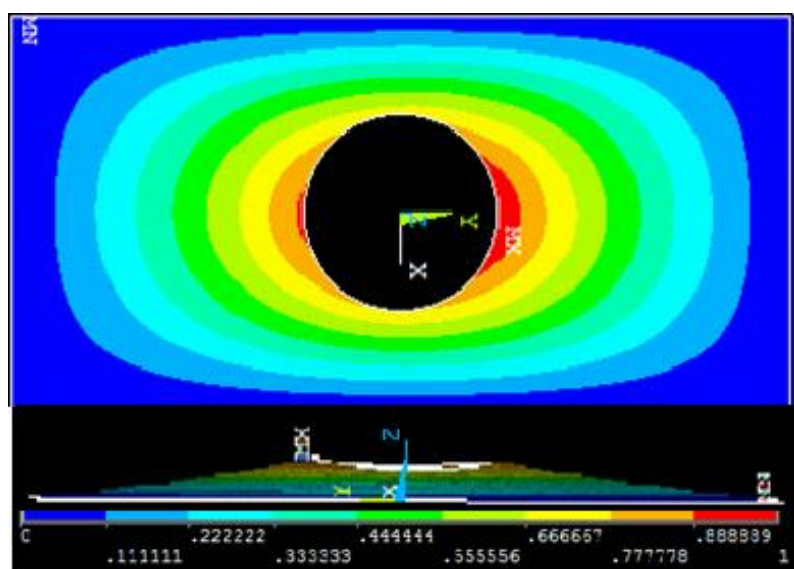

Figura 7 - Placa com furo utilizada para verificação do modelo computacional, com $L / h=20$, no seu primeiro estado de flambagem.

\section{CONCLUSÃO}

- A aplicação do MEF através da utilização do elemento de casca SHELL281 se mostra aplicável à análise da carga crítica de flambagem biaxial de placas de material compósito, laminadas e simétricas.

- A verificação dos modelos computacionais para placas compósitas laminadas com furo (onde foi utilizado o elemento SHELL99) e sem furo (onde foi utilizado o elemento SHELL93) comprova que o elemento SHELL281 pode ser utilizado para análise de flambagem elástica, biaxial, em placas delgadas laminadas, sejam estas com furo ou sem.

- Com a comparação dos gráficos da Figura 6 e os resultados da Tabela 2 pode-se concluir que a carga crítica de flambagem diminui à medida que a espessura da placa diminui.

- A utilização do MEF apresenta um baixo tempo operacional para obtenção da carga crítica de flambagem biaxial para placas de material compósito, fazendo com que análises possam ser mais ágeis, reduzindo o tempo dedicado aos projetos estruturais.

\section{AGRADECIMENTOS}

Os autores agradecem à CAPES e ao CNPq pelas bolsas de pesquisa concedidas e à FURG pelo apoio 


\section{REFERÊNCIAS BIBLIOGRÁFICAS}

1. Soo Kim Y. Biaxial Buckling of Laminated Composite Plates [thesis]. Montreal (QC): University of Concórdia; 1995.243 p.

2. Megson THG. Structural and Stress Analysis. Philadelphia: Ed. Elsevier Butterworth-Heinemann; 2005. $744 \mathrm{p}$.

3. Austin CD. Buckling of symmetric laminated fiberglass reinforced plastic (FRP) plates [dissertation]. Pittsburgh (PA): University of Pittsburgh; 2003. 173p.

4. Baba BO, Baltaci A. Buckling Characteristics of Symmetrically and Antisimmetrically Laminated Composite Plates with Central Cutout. Applied Composite Materials. 2007;14(4):265-276, doi: 10.1007/ s10443-007-9045-z.

5. Barbero EJ. Finite Element Analysis of Composite Material. Boca Raton: Taylor \& Francis Group; 2007. $359 \mathrm{p}$.

6. Al-Qablan H, Dwairi H, Shatarat N, Rosan T, Al-Qablan T. Stability Analysis of Composite Panels with Stiffeners and Circular Cutouts. Jordan Journal of Civil Engineering. 2010;4(2):119-131.

7. Joshi A, Reddy PR, Krishnareddy VN, Sushma CV. Buckling Analysis of Thin Carbon/Epoxy Plate with Circular Cut-outs Under Biaxial Compression By Using FEA. International Journal of Research in Engineering and Technology (IJRET). 2013;2(10): 296-301.

8. Ansys. Analysis Guide. Cannonsburg: Ansys Inc; 2004.

9. Zienkiewicz OC, Taylor RL. The Finite Element Method. New York: McGraw-Hill Book Company; 1989. $689 \mathrm{p}$.

10. Bathe KJ. Finite Element Procedures. New Jersey: Prentice-Hall; 1996. 735 p.

11. Real MV, Isoldi LA. Finite Element Buckling Analysis of Uniaxially Loaded Plates with Holes. In: Southern Conference on Computational Modeling - MCSUL. Rio Grande, RS: Universidade Federal do Rio Grande - FURG; c2010. p. 669-73.

12. Ansys. Element Reference Manual (version 12.1). Canonsburg: Technology Drive; 2009.

13. Madenci E, Guven I. The Finite Element Method and Applications in Engineering Using ANSYS®. New York: Ed. Springer; 2006. 686 p.

14. Przemieniecki JS. Theory of Matrix Structural Analysis. Mineola: Ed. Dover Publications; 1985. 480 p. 15. Ansys. User's Manual (version 10.0). Houston: Swanson Analysis System Inc; 2005.

16. Mendonça PTR. Materiais Compostos \& Estruturas Sanduíche: Projeto e Análise. Barueri: Editora Manole; 2005. $625 \mathrm{p}$.

17. Jones RM. Mechanics of Composite Materials. Philadelphia: Taylor \& Francis; 1999.519 p. 